\title{
Pitting Corrosion of Type 316L Stainless Steel Elaborated by the Selective Laser Melting Method: Influence of Microstructure
}

\author{
V. Vignal, C. Voltz, S. Thiébaut, M. Demésy, O. Heintz, and S. Guerraz
}

Submitted: 17 December 2020 / Revised: 11 February 2021 / Accepted: 18 February 2021 / Published online: 17 March 2021

\begin{abstract}
The microstructure of two sets of 316 $\mathrm{L}$ alloys (SLM and wrought structure) is determined using SPECTROMAXx stationary metal analyzer, FE-SEM/EDS and XRD. The physical-chemical properties of the passive films are also investigated by means of XPS, Auger after sputtering and electrochemical impedance spectroscopy measurements. Differences and similarities between the two sets of alloys are then identified. The corrosion behavior of alloys is investigated in $\mathrm{NaCl}$ solution at the macro- and microscale (microcapillary technique). It was found that the inclusion/particles cleanliness is the first-order parameter explaining differences between $316 \mathrm{~L}$ (WS) and 316L(SLM). In the absence of particles (pure matrix), the two sets of alloys have the same corrosion behavior. Residual stresses, the average grain size, the PREN and the passive films properties are of second order.
\end{abstract}

Keywords austenite, passive film, pitting corrosion, selective laser melting

\section{Introduction}

Additive manufacturing (AM) is defined as the process of adding materials layer-by-layer to manufacture parts of threedimensional work pieces (Ref 1, 2). Different AM technologies have been developed, such as direct metal laser sintering (DMLS), direct metal deposition (DMD), electron beam melting (EBM) or selective laser melting (SLM) (Ref 2). SLM enables the elaboration of metallic alloys and the fabrication of engineering components directly from metallic powder. Metal powder layers are fused by a laser source in a layer-by-layer manner into the required three-dimensional (3D) structure (Ref 2). The interaction of the metal powder and the laser beam raises the temperature to the melting point. It has been pointed out that the primary parameters that govern the microstructure of a $3 \mathrm{D}$ printed specimen are the laser power and the laser scan speed (Ref 3$)$.

This invited article is part of a special topical focus in the Journal of Materials Engineering and Performance on Additive Manufacturing. The issue was organized by Dr. William Frazier, Pilgrim Consulting, LLC; Mr. Rick Russell, NASA; Dr. Yan Lu, NIST; Dr. Brandon D. Ribic, America Makes; and Caroline Vail, NSWC Carderock.

V. Vignal and O. Heintz, ICB, UMR 6303 CNRS - Université de Bourgogne Franche Comté, BP 47870, 21078 Dijon, France; and Laboratoire Interactions Matériaux Procédés Environnements, LRC LIMPE $n^{\circ}$ DAM-VA-11-02, Dijon, France; C. Voltz, S. Thiébaut, and M. Demésy, Laboratoire Interactions Matériaux Procédés Environnements, LRC LIMPE $n^{\circ}$ DAM-VA-11-02, Dijon, France; and CEA, DAM, Centre d'études de Valduc, 21120 Is sur Tille, France; S. Guerraz, GMP ADDITIV', 74800 St Pierre en Faucigny, France. Contact e-mail: vincent.vignal@u-bourgogne.fr.
Due to the elaboration process conditions, alloys derived from SLM have specific microstructure when compared to alloys elaborated from conventional processing. A fine microstructure with columnar grains along the built direction is observed (Ref 4-7). The width of the elongated grains is $\sim 10 \mu \mathrm{m}$. The microstructure is almost fully dense (low density of pores). In the case of $316 \mathrm{~L}$ stainless steel, intercellular segregation of $\mathrm{Mo}, \mathrm{Cr}$ and $\mathrm{Si}$, resulting in creation of nonequilibrium eutectic ferrite is sometimes found (Ref 6). Transmission electron microscopy investigations (Ref 7) reveal the existence of a very fine dislocation cell structure in the asbuilt SLM sample with similarities to the deformation substructures obtained after severe plastic deformation.

The corrosion behavior of $316 \mathrm{~L}$ derived from SLM may be significantly different from that of the alloy elaborated by classical methods (Ref 3, 8-19). Most of the papers show that 316L derived from SLM exhibits better corrosion resistance than $316 \mathrm{~L}$ with wrought structure. However, the results can be relatively scattered. This scatter has never been discussed or interpreted. The main reason is that in all these studies, some information is often missing about the composition and microstructure of the substrate (content of minor elements such as carbon, sulfur and nitrogen, the presence of inclusions...) and the properties of the passive film (composition, thickness, density of dopants...).

According to the American Society Testing and Materials (ASTM), stainless steels are defined by grade composition ranges, and not by specifications. Therefore, the PREN of 316L is between 22.6 and 29.5 (first row in Table 1). In addition, large $\mathrm{MnS}$ inclusions can be found for sulfur contents greater than $200 \mathrm{ppm}$. Therefore, the chemical composition and microstructure must be determined accurately to ensure that studied alloys (SLM vs classical samples, for example) are comparable and to interpret correctly differences observed in the corrosion behavior.

In this paper, the microstructure of two $316 \mathrm{~L}$ alloys (elaborated by SLM and from conventional processing) is investigated using SPECTROMAXx stationary metal analyzer, 
Table 1 Chemical composition of alloys (wt.\%) and values of the PREN (PREN $=\mathrm{Cr}+3.3 \times \mathrm{Mo}+16 \times \mathrm{N}$ )

\begin{tabular}{|c|c|c|c|c|c|c|c|c|c|c|c|}
\hline & $\mathrm{Cr}$ & $\mathbf{N i}$ & Мo & Mn & $\mathbf{S i}$ & C & $\mathbf{N}$ & $\mathbf{P}$ & $\mathbf{S}$ & $\mathbf{F e}$ & PREN \\
\hline ASTMA240/A240M & $16-18$ & $10-14$ & $2-3$ & $<2$ & $<0.75$ & $<300 \mathrm{ppm}$ & $<1000 \mathrm{ppm}$ & $<450 \mathrm{ppm}$ & $<300 \mathrm{ppm}$ & \multirow[t]{4}{*}{ Bal. } & $22.6-29$. \\
\hline 316L(WS) & 16.45 & 10.13 & 2.06 & 1.66 & 0.51 & $160 \mathrm{ppm}$ & 700 ppm & $200 \mathrm{ppm}$ & $<5 \mathrm{ppm}$ & & 24.4 \\
\hline 316L powder & 17.69 & 13.01 & 2.45 & 0.91 & 0.41 & $150 \mathrm{ppm}$ & $850 \mathrm{ppm}$ & $180 \mathrm{ppm}$ & $52 \mathrm{ppm}$ & & 27.1 \\
\hline 316L(SLM) & 17.89 & 12.56 & 2.55 & 0.49 & 0.45 & $150 \mathrm{ppm}$ & 830 ppm & 190 ppm & $46 \mathrm{ppm}$ & & 27.6 \\
\hline \multicolumn{12}{|l|}{ 316L(SLM-1050) } \\
\hline $304 \mathrm{~L}$ & 18.17 & 10.13 & 0.2 & 1.13 & 0.4 & $180 \mathrm{ppm}$ & $730 \mathrm{ppm}$ & & 44 ppm & & 20 \\
\hline $316 \mathrm{~L}$ & 17.2 & 12.6 & 2.5 & 1.43 & 0.4 & 170 ppm & $300 \mathrm{ppm}$ & & 8 ppm & & 25.9 \\
\hline 904L & 19.55 & 24.2 & 4 & 1.41 & 0.2 & 210 ppm & 740 ppm & & $2 \mathrm{ppm}$ & & 34 \\
\hline
\end{tabular}

surface observation methods (optical microscopy and fieldemission scanning electron microscopy, FE-SEM) and x-ray diffraction (XRD, $\sin ^{2} \psi$ method). The physical-chemical properties of the passive films are also determined by means of x-ray photoelectron spectroscopy (XPS), Auger electron spectroscopy (AES) after sputtering and electrochemical impedance spectroscopy (EIS) measurements (Mott-Schottky analysis). Differences and similarities between the two alloys are then identified. The corrosion behavior is then studied in $3.5 \% \mathrm{NaCl}$ at $25{ }^{\circ} \mathrm{C}$ using potentiodynamic tests. Differences in the corrosion behavior are analyzed considering the composition and microstructure (PREN, average grain size, the presence of particles/inclusions) as well as the properties of the passive film.

\section{Experimental Procedure}

\subsection{Materials and Surface Preparation}

Two 316L stainless steel alloys were investigated, including an alloy with a wrought structure (noted $316 \mathrm{~L}(\mathrm{WS})$ ) and an alloy elaborated by SLM (316L(SLM)). The chemical composition of $316 \mathrm{~L}(\mathrm{WS})$ is reported in Table 1. It was solutionannealed at $1050{ }^{\circ} \mathrm{C}$ for $15 \mathrm{~min}$ and quenched in water. To establish a relationship between the PREN and the pitting potential, three other alloys with a wrought structure were studied (noted 304L, 316L and 904L in Table 1).

The SLM alloy (noted 316L(SLM)) was elaborated by the use of an EOS M290 (EOS GmbH, Krailling, Germany) with an Yb-fiber laser (wavelength of $1070 \mathrm{~nm}$ and power of $400 \mathrm{~W}$ ) having a laser diameter of $100 \mu \mathrm{m}$ (corresponding to the hatch spacing). The input energy density was kept fixed at $100 \mathrm{~J} \mathrm{~mm}^{-3}$. Experiments were conducted in an inert nitrogenpurged atmosphere. A cross-hatching strategy with a rotation angle of $60^{\circ}$ between consecutive layers was selected. The chemical composition of the powder (average particle size of $32.9 \pm 11.3 \mu \mathrm{m}$, error = standard deviation) is reported in Table 1. A heat treatment was then applied to $316 \mathrm{~L}$ (SLM) in air. It consists in rising temperature up to $1050{ }^{\circ} \mathrm{C}$ in $150 \mathrm{~min}$ $\left(420{ }^{\circ} \mathrm{C} / \mathrm{h}\right.$ ) from room temperature, maintaining $1050{ }^{\circ} \mathrm{C}$ for $30 \mathrm{~min}$ and applying water quenching. This heat-treated alloy is noted $316 \mathrm{~L}(\mathrm{SLM}-1050)$. After heat treatment, a 1-mm thick layer was removed by grinding samples.

316L(WS), 316L(SLM) and 316L(SLM-1050) samples (height of $5 \mathrm{~mm}$ and diameter of $4 \mathrm{~cm}$ ) were embedded in an epoxy resin. In the case of $316 \mathrm{~L}$ (SLM) and 316L(SLM-1050), the surface studied is perpendicular to the build-up direction of the additively manufactured workpieces (XY-plane). All samples were ground using emery papers (1200, 2400 and 4000 grits) and polished with diamond pastes $(6,3$ and $1 \mu \mathrm{m})$. A specific vibratory polishing (VibroMet 2 vibratory polisher from Buehler) was then applied to remove the cold worked layer generated during the previous steps.

\subsection{Surface Analysis and XRD Measurements}

The chemical composition of native passive films was determined from XPS and AES measurements. A PHI Versaprobe 5000 apparatus with a monochromated Al Kal line (energy of $1486.7 \mathrm{eV}$, power of $50 \mathrm{~W}$ and $\mathrm{x}$-ray spot diameter of $200 \mu \mathrm{m}$ ) was used for XPS analyses. The C1s peak from pollution (at $284.8 \mathrm{eV}$ ) was considered for the energy calibration. Spectra were treated with the CasaXPS software package.

AES measurements were carried out using a PHI 5000 Versaprobe instrument, with an electron beam diameter of $500 \mu \mathrm{m}$. Depth profiling was performed using $500 \mathrm{eV}$ argon ions with a sputtering rate of $2 \mathrm{~nm} \mathrm{m^{-1 }}$. This sputtering rate was measured on a pure $\mathrm{SiO}_{2}$ thermal oxide. Analyzed peaks are $\mathrm{O}(510 \mathrm{eV}), \mathrm{C}(275 \mathrm{eV}), \mathrm{Fe}(600 \mathrm{eV}), \mathrm{Ti}(421 \mathrm{eV}), \mathrm{Cr}$ $(531 \mathrm{eV}), \mathrm{Ni}(849 \mathrm{eV})$ and Mo $(184 \mathrm{eV})$. Acquisitions in direct mode were derivated for the measurement of intensities. Data were treated with the Multipack software package.

Residual stresses were measured using the XRD technique and the $\sin ^{2} \psi$ method (Ref 20). A D8 Discovery Bruker fourcircle diffractometer equipped with a large area detector (GADDS) was used. The x-rays were generated by a Co tube $\left(\lambda_{k \alpha}=0.179 \mathrm{~nm}\right)$ and the surface area analyzed was $3.1 \mathrm{~mm}^{2}$.

\subsection{Electrochemical Measurements}

All electrochemical experiments were carried out in 3.5 wt. $\% \mathrm{NaCl}$ at $25^{\circ} \mathrm{C}$ using a PGSTAT128 AUTOLAB potentiostat/galvanostat. Experiments were performed at the global scale using a classical three-electrode cell. Potentials were measured vs. saturated calomel electrode (SCE) and the counter electrode was made of platinum grid $\left(5 \times 5 \mathrm{~cm}^{2}\right)$. Polarization curves were plotted from $-400 \mathrm{mV}$ vs. SCE up to $1 \mathrm{~V}$ at a potential scan rate of $1 \mathrm{mV} \mathrm{s}^{-1}$.

Mott-Schottky analyses were performed to investigate the semiconducting properties of native passive films. Electrochemical impedance spectroscopy (EIS) measurements were performed at $1.5 \mathrm{kHz}$. The Mott-Schottky plots were obtained by sweeping the potential range in the anodic direction, from -1000 to $+1000 \mathrm{mV}$ SCE. Potentials were applied by successive steps of $50 \mathrm{mV}$, with an amplitude sinusoidal voltage perturbation of $20 \mathrm{mV}$. Capacitance values were 
calculated from the relation $C=\left(-2 \pi f Z_{\text {im }}\right)^{-1}$, where $f$ is the frequency and $Z_{\mathrm{im}}$ is the imaginary part of the impedance.

\section{Results and Discussion}

\subsection{Microstructures}

316L(WS), 316L(SLM) and 316L(SLM-1050) have comparable carbon content (150-160 ppm in Table 1) and very low sulfur level $(<50 \mathrm{ppm}$ in Table 1$)$. The pitting resistance equivalent number (PREN) of 316L(SLM) and 316L(SLM1050) is significantly greater than that of $316 \mathrm{~L}(\mathrm{WS})$, Table 1. The difference (of about 3) must be taken into account when interpreting the corrosion results.

Figure 1(a), (b), (c) and (d) shows the microstructure of the three samples after etching (in $50 \% \mathrm{vol} . \mathrm{HCl}$ at $2 \mathrm{~V}$ for $10 \mathrm{~s}$ ). Equiaxed grains are observed in $316 \mathrm{~L}(\mathrm{WS})$, Figure 1(a). Annealing twins are also present in some grains. Both the hatching pattern and fine grains are visible in $316 \mathrm{~L}$ (SLM), Fig. 1(b). After heat treatment, the hatching pattern is no longer visible, and only coarse grains are found, Fig. 1(c). The average grain size was determined using the circular intercept method according to ASTM E112. The average grain size is 53.4, 15.9 and $31.8 \mu \mathrm{m}$ for $316 \mathrm{~L}(\mathrm{WS}), 316 \mathrm{~L}(\mathrm{SLM})$ and $316 \mathrm{~L}$ (SLM1050 ), respectively. These results show that $316 \mathrm{~L}$ (SLM) has the finest microstructure.

316L(WS) contains mixed oxide microparticles having a diameter between 1 and $5 \mu \mathrm{m}$ (image insert in Fig. 1a). Al, Mg, $\mathrm{Mn}, \mathrm{Si}, \mathrm{Ti}$ and $\mathrm{Ca}$ are constituent elements of these microparticles. For example, energy dispersive spectroscopy (EDS) analysis of the microparticle in Fig. 1(a) yields (at.\%) 63.5\% O,
$10.8 \% \mathrm{Si}, 10.2 \% \mathrm{Al}, 8.5 \% \mathrm{Ca}, 3.2 \% \mathrm{Ti}, 1.6 \% \mathrm{Mg}$ and $0.9 \%$ $\mathrm{Mn}$. This analysis was performed using JEOL JSM-7600F FESEM. It was already shown (Ref 21, 22) that microparticles containing $\mathrm{CaO}$ are precursor sites for pitting corrosion in stainless steels. By contrast, no $\mathrm{MnS}$ inclusions were found. In 316L(SLM) and 316L(SLM-1050), no mixed oxide microparticles, no MnS inclusions and no pores were found. The two samples contain spherical silicate nanoparticles (diameter $<<1 \mu \mathrm{m}$, Fig. 1d) composed mostly of $\mathrm{O}$ (51.9 \pm 4.1 at.\%), $\mathrm{Si}(16.1 \pm 1.1$ at.\%), $\mathrm{Cr}(13.2 \pm 2.8$ at. $\%)$ and $\mathrm{Mn}(9.1 \pm 1.1$ at.\%). Therefore, differences observed between samples in the average grain size and in the nature of particles must be taken into account when interpreting the corrosion results.

Residual stresses were measured using the $\sin ^{2} \psi$ method (Ref 20). A linear relationship was systematically found between the variation of the Bragg's angle, $\Delta 2 \theta$, and $\sin ^{2} \psi$, Fig. 2(a) and (b). The same slope was found for the three samples, corresponding to residual stress values of $-66 \pm 24$ and $-24 \pm 14 \mathrm{MPa}$ in the radial and orthoradial directions, respectively. As expected (vibratory polishing), residual stresses are very low. The same level of residual stresses was obtained in the three samples. Therefore, differences observed in the corrosion behavior cannot be interpreted considering this parameter.

\subsection{Properties of Passive Films}

There is a limited number of papers about the physicalchemical properties of passive films formed on $316 \mathrm{~L}$ alloys elaborated by SLM. AES analyses (Ref 23) do not show significant differences in the chemical composition and thickness of the passive films formed in alkaline solution under
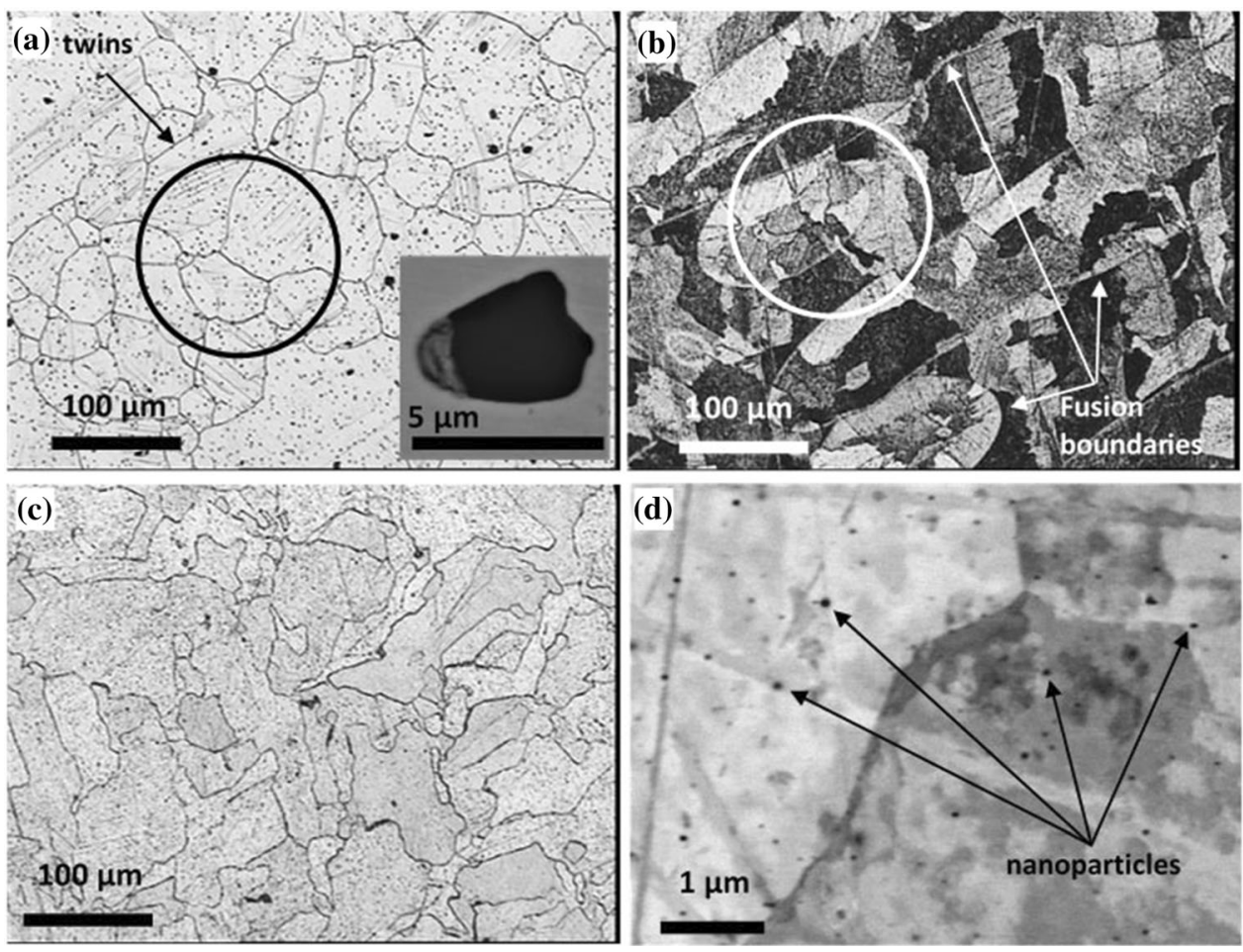

Fig. 1 Optical images after etching in $50 \% \mathrm{HCl}$ at $2 \mathrm{~V}$ for 10 seconds of (a) 316L(WS) (insert image: mixed oxide microparticle), (b) 316L(SLM) and (c) 316L(SLM-1050). (d) FE-SEM image after surface preparation of silicate nanoparticles in 316L(SLM). The circle in (a) represents the diameter of the capillary used for local electrochemical measurements 

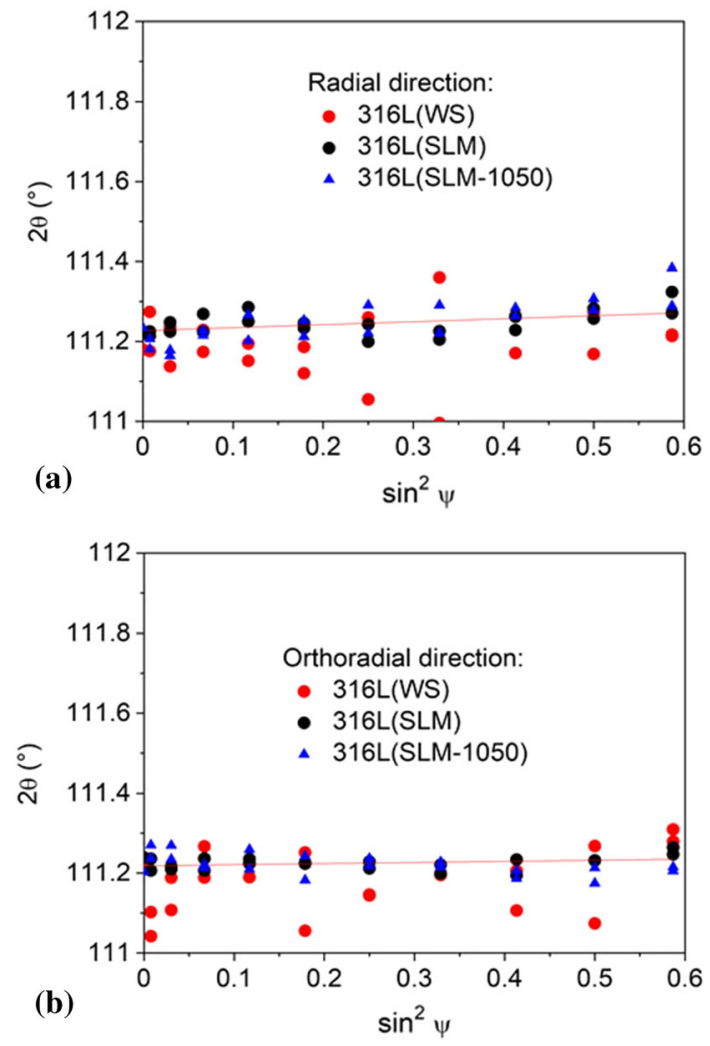

Fig. $22 \theta$ vs. $\sin ^{2} \psi$ plots after surface preparation: (a) radial and (b) orthoradial directions

potentiostatic conditions for 12 hours. By contrast, XPS and TEM investigations (Ref 24) reveal some differences in the structure of these passive films. It was proposed that these differences might lead to a more protective passive film on the sample elaborated by SLM. In addition, there are no data about the physical-chemical properties of native passive films.

XPS experiments were carried out to characterize the composition of the three native passive films. Mo3d spectra were decomposed as proposed in (Ref 25), Figure 3(a) and (b). $\mathrm{Mo}^{6+}$ and $\mathrm{Mo}^{4+}$ species were found, and no differences were observed between the three samples. $\mathrm{C} 1 s, \mathrm{O} 1 s, \mathrm{Fe} 2 p$ and $\mathrm{Cr} 2 p$ spectra were decomposed into classical contributions according to (Ref 26, 27). A peak was found at $283 \mathrm{eV}$ in the $\mathrm{C} 1 s$ spectrum of $316 \mathrm{~L}(\mathrm{SLM}-1050)$ which was attributed to the presence of carbides, Fig. 3(c). This study is an example of the formation of carbides due to the heat treatment conditions described in section 2.1. Depending on the heat treatment strategy (Ref 17, 18, 28, 29), precipitation can occur and/or the distribution of dislocations and alloying elements, the grain size and orientation and the nature of grain boundaries can be modified. The ratio $\mathrm{O}^{2-} / \mathrm{OH}^{-}$in the native passive films was calculated from the O1s spectra, Fig. 3(d). Numerical values are reported in Table 2. The highest value was found for 316L(SLM-1050), of about 2 (between 1.3 and 1.4 for 316L(WS) and 316L (SLM)). This ratio plays also an important role in pitting corrosion (Ref 30 ). Indeed, passivity of metallic alloys is usually attributed to the presence of oxides at the specimen surface rather than hydroxides. Therefore, the native passive film formed on 316L(SLM-1050) is slightly richer in oxides than the two others.
Regarding alloying elements, the native passive film on 316L(SLM) contains the lowest amount of Fe-based species (oxides and hydroxides), Fig. 4(a). On the other hands, the native passive films on $316 \mathrm{~L}$ (SLM) and 316L(SLM-1050) contain the lowest amount of Cr-based species (oxides and hyroxides), Fig. 4(b). The ratio $\mathrm{Cr} / \mathrm{Fe}$ in the native passive films is more relevant to interpret the corrosion resistance of alloys rather than the $\mathrm{Cr}$ and $\mathrm{Fe}$ contents. It was already shown that the greater the ratio $\mathrm{Cr} / \mathrm{Fe}$ in the passive film, the higher the corrosion resistance of the alloy (Ref 31,32$)$. The values of $\mathrm{Cr} /$ Fe were calculated from AES profiles, Fig. 5 and Table 2. The same value of $\mathrm{Cr} / \mathrm{Fe}$ was found in the three cases (values around 0.5 ). This ratio is less than unity, indicating that all native passive films are richer in iron-containing species than in chromium-containing ones.

The thickness of the native passive films on $316 \mathrm{~L}(\mathrm{WS})$ and 316L (SLM) is around $1 \mathrm{~nm}$ (Fig. 5a and b) and Table 2). The thickness is regarded as the sputtering distance at which oxygen content reduces to half relative to that at the surface. The depth profile of oxygen on $316 \mathrm{~L}$ (SLM-1050) is different from that on the two other samples, Fig. 5(c). This could mean that the passive film is thicker or that the thickness is comparable but the sputtering rate is slower (passive film enriched with oxides which are more difficult to sputter than hydroxides).

Figure 6 shows the Mott-Schottky plots of the native passive films. All plots reveal two linear parts corresponding to Mott-Schottky-type behaviors (Ref 33$)$. For applied potentials less than $-600 \mathrm{mV}$ vs. SCE, a p-type semiconducting behavior which is attributed to the predominant formation of chromium oxide in the inner part of passive films is found. In the anodic region (potentials greater than $-600 \mathrm{mV}$ vs. SCE), the capacitance represents the behavior of a $n$-type semiconductor characterizing the outer hydroxide layer of native passive films. The density of acceptors and donors was calculated from the negative and positive slopes, respectively (Eq 1).

$N=\frac{2}{\varepsilon \cdot \varepsilon_{0} \cdot q \cdot p}$

where $\varepsilon$ is the relative permittivity $(\varepsilon=15.6(\operatorname{Ref} 23)), \varepsilon_{0}$ is the vacuum permittivity $\left(8.854 \times 10^{-12} \mathrm{~F} \mathrm{~m}^{-1}\right), q$ is the electron charge $\left(1.602 \times 10^{-19} \mathrm{C}\right)$ and $p$ is the slope $\left(\mathrm{F}^{-2} \mathrm{~m}^{4} \mathrm{~V}^{-1}\right)$. Numerical values of the density of acceptors $\left(N_{\mathrm{a}}\right)$ and donors $\left(N_{\mathrm{d}}\right)$ are reported in Table 2. Results obtained on $316 \mathrm{~L}(\mathrm{WS})$ and $316 \mathrm{~L}(\mathrm{SLM}-1050)$ are similar. The native passive film formed on $316 \mathrm{~L}(\mathrm{SLM})$ contains the highest density of dopants (both acceptors and donors). This sample has the finest microstructure and therefore the highest density of grain boundaries. However, differences between the three samples are very small. The density of dopants in $316 \mathrm{~L}$ (SLM) is 1.4-1.8 times higher than in the other samples.

AES and XPS results show that the native passive films have the same chemical composition. The native passive film on SLM(SLM-1050) is slightly thicker than on the two other samples. In addition, electrochemical measurements reveal that differences in the density of dopants between the three samples are small.

\subsection{Corrosion Behavior of Samples in 3.5wt.\% NaCl}

Figure 7(a) shows the polarization curves of $316 \mathrm{~L}(\mathrm{WS})$, $316 \mathrm{~L}(\mathrm{SLM})$ and $316 \mathrm{~L}(\mathrm{SLM}-1050)$ in $3.5 \% \mathrm{NaCl}\left(25^{\circ} \mathrm{C}\right)$ at the global scale. It can be observed that the method of elaboration 

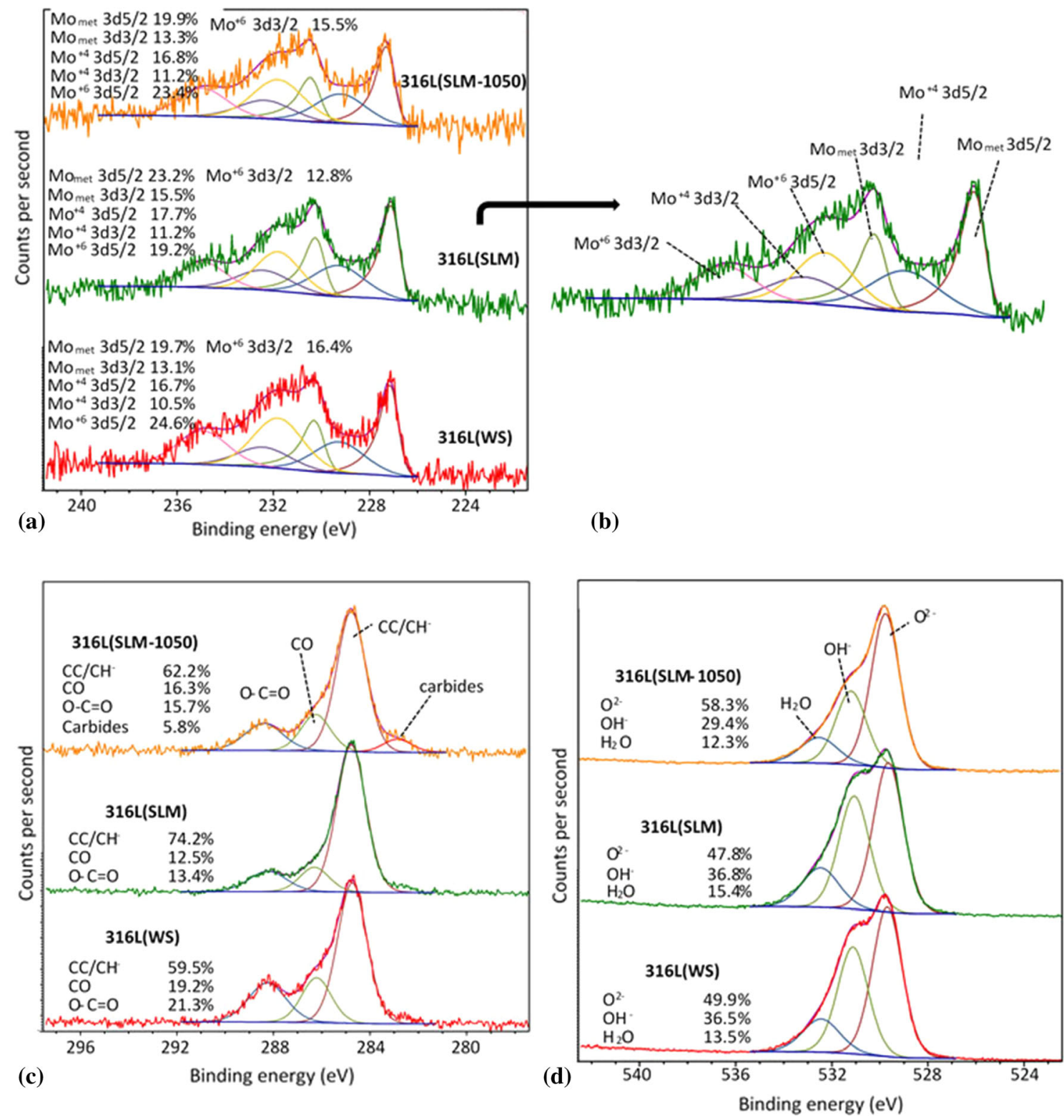

Fig. 3 XPS spectra of 316L(WS), 316L(SLM) and 136L(SLM-1050) after surface preparation: (a-b) Mo3d levels, (c) C1s and (d) O1s

Table 2 Quantitative data derived from (*) Auger, (**) XPS and (**) EIS measurements after surface preparation

\begin{tabular}{|c|c|c|c|c|c|}
\hline & Thickness* (nm) & $\mathbf{C r} / \mathbf{F e}^{*}$ & $\mathrm{O}^{2-} / \mathrm{OH}^{-* *}$ & $\mathrm{Na}^{* *}\left(\times 10^{12} \mathrm{~cm}^{-3}\right)$ & $\mathrm{Nd}^{* * *}\left(\times 10^{12} \mathrm{~cm}^{-3}\right)$ \\
\hline 316L(WS) & 1 & 0.5 & 1.4 & 1.2 & 1 \\
\hline 316L(SLM) & 1 & 0.5 & 1.3 & 1.7 & 1.8 \\
\hline 316L(SLM-1050) & 2.5 & 0.5 & 2 & 1.3 & 1.3 \\
\hline
\end{tabular}

and the heat treatment have no influence on the current density in the cathodic branch. The main cathodic reaction is the oxygen reduction reaction (ORR, reaction 2).

$\mathrm{O}_{2}+2 \mathrm{H}_{2} \mathrm{O}+4 \mathrm{e}^{-} \rightarrow 4 \mathrm{OH}^{-}$

316L(SLM) exhibits passive behavior. No stable and metastable pitting is observed in the anodic domain, Fig. 7(a). By contrast, stable pitting is observed in 316L(WS) and $316 \mathrm{~L}(\mathrm{SLM}-1050)$ at an applied potential of 0.5 and $0.4 \mathrm{~V}$ vs. SCE, respectively. To confirm that stable pitting occurs in 316L(SLM-1050), the potential of $1 \mathrm{~V}$ vs SCE was maintained at the end of the polarization curve for a sufficiently long time. The current density increases continuously to values greater than $1 \mathrm{~mA} / \mathrm{cm}^{2}$ (and the pits were found to be larger than right after the polarization curve). The current peaks observed in the passive range of the polarization curve of 316L(SLM-1050) correspond to potential transients (metastable pitting) rather than oxidation peaks. Indeed, two polarization curves were 


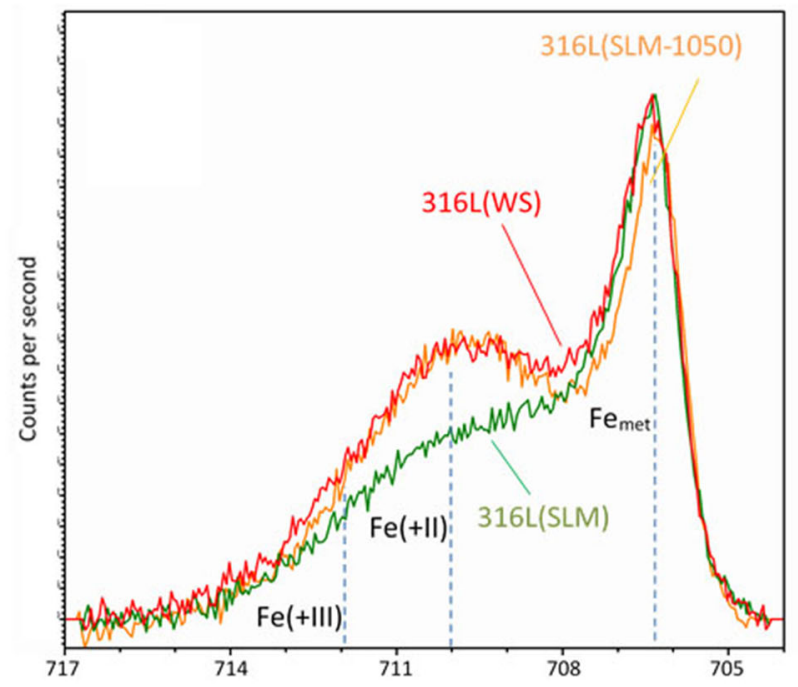

(a)

Binding energy (eV)

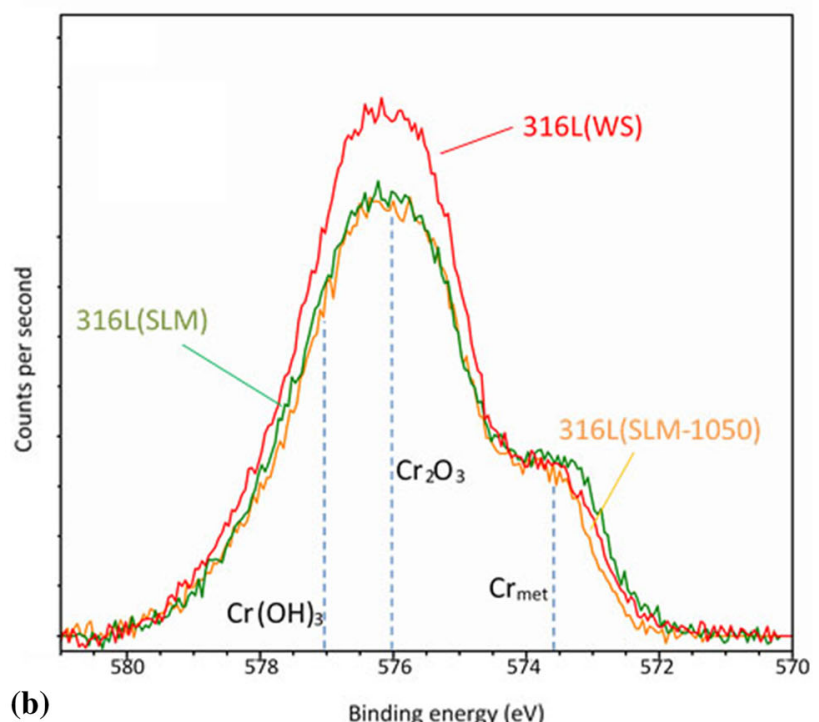

Fig. 4 XPS spectra of 316L(WS), 316L(SLM) and 136L(SLM1050) after surface preparation: (a) Fe2p, (b) Cr2p levels

plotted, and these peaks were not systematically observed. Figure 8 shows pits observed in 316L(WS) and 316L(SLM1050) after polarization curves. They were significantly larger in the wrought structure than in the $316 \mathrm{~L}(\mathrm{SLM}-1050)$. The influence of the microstructure and elaboration method on the pit propagation stage is an important scientific issue that we will be studied in the future.

Considering the results presented in the previous sections, two different assumptions may explain the excellent corrosion resistance of $316 \mathrm{~L}(\mathrm{SLM})$ with respect to $316 \mathrm{~L}(\mathrm{WS})$ : the greatest value of the PREN (chemical composition of the matrix) and/or the absence of mixed oxide microparticles.

Figure 7(b) shows the evolution of the pitting potential vs the PREN value. To determine this evolution, global polarization curves of additional austenitic alloys with wrought structure were plotted in $3.5 \% \mathrm{NaCl}$ at $25{ }^{\circ} \mathrm{C}$, after vibratory polishing. Among these austenitic alloys, there is type $304 \mathrm{~L}$ stainless steel $($ PREN $=20)$, a second type 316L $($ PREN $=25)$ and a super-austenitic 904L stainless steel $(\mathrm{PREN}=35)$,
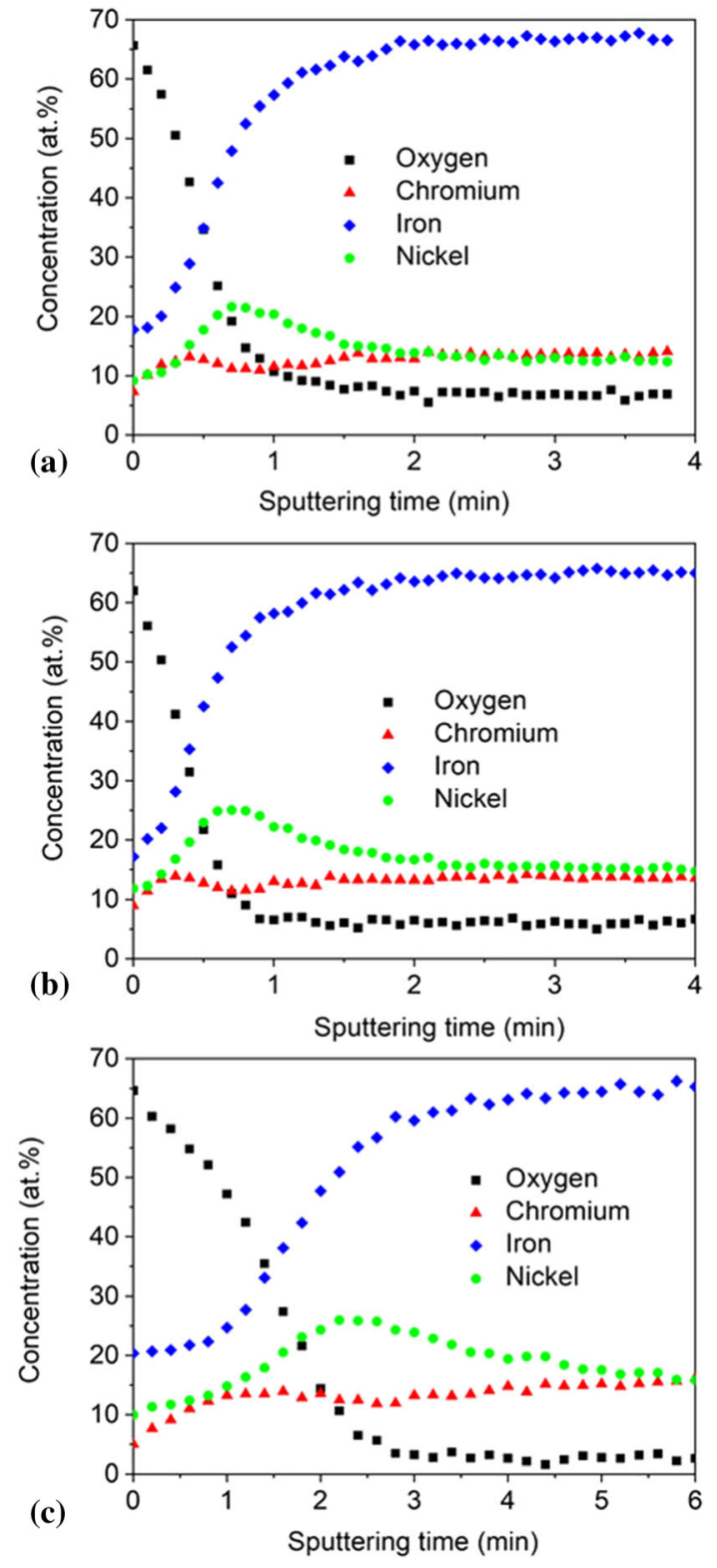

Fig. 5 Auger depth profiles of oxygen and alloying elements (Fe, Cr, Ni) for: (a) 316L(WS), (b) 316L(SLM) and (c) 316L(SLM-1050) after surface preparation

Table 1. All these alloys have very low carbon $(<150 \mathrm{ppm})$ and sulfur $(<50 \mathrm{ppm})$ contents. They contain mixed oxide microparticles (as that shown in Fig. 1a). A linear relationship was found between the pitting potential and the PREN value (dotted line in Fig. 7b). According to this relationship, $316 \mathrm{~L}$ (SLM) which have a PREN of 27.6 should exhibit stable pitting at around $630 \mathrm{mV}$ vs SCE. This is not in good agreement with the results shown in Fig. 7a (no stable pitting in $316 \mathrm{~L}(\mathrm{SLM})$ ). This suggests that the PREN is not the first-order parameter controlling pitting corrosion of the studied alloys.

Local polarization curves were then plotted in sites of 316L(WS) containing the matrix without mixed oxide microparticles, Fig. 9. The measurements were performed under the same experimental conditions than at the global scale $\left(3.5 \% \mathrm{NaCl}\right.$ at $\left.25{ }^{\circ} \mathrm{C}, 1 \mathrm{mV} / \mathrm{s}\right)$ using the electrochemical microcell technique (Ref 33-36) and capillaries with a diameter 


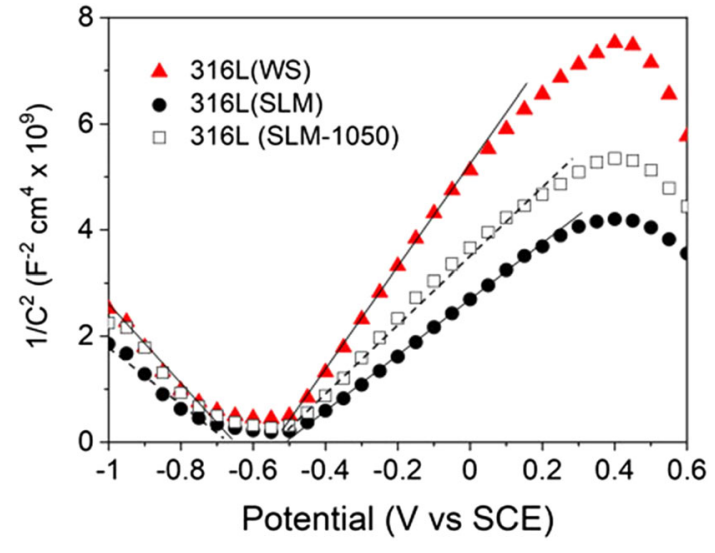

Fig. 6 Mott-Schottky plots for the native passive films after surface preparation
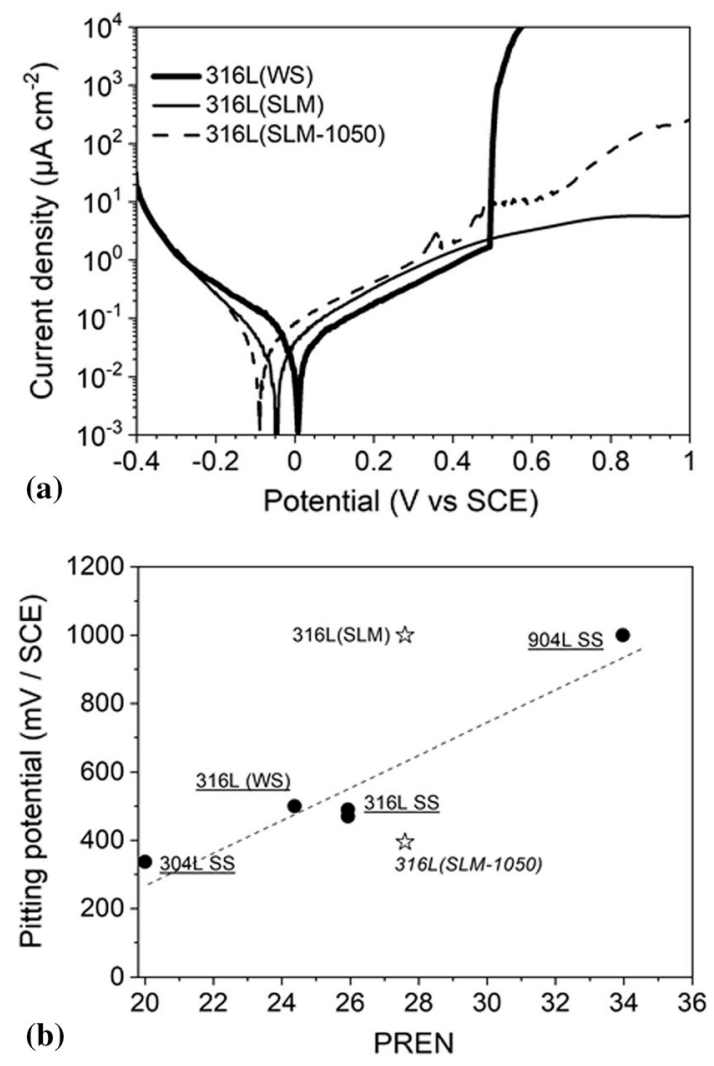

Fig. 7 (a) Global polarization curves $\left(3.5 \% \mathrm{NaCl}\right.$ à $25^{\circ} \mathrm{C}, 1 \mathrm{mV} \mathrm{s}$ $\left.{ }^{1}\right)$ of the different samples after surface preparation. (b) Relationship between pitting potential derived from global polarization curves and PREN for different austenitic alloys

of $154 \mu \mathrm{m}$. As shown in Fig. 1(a), several grains and grain boundaries are present within the investigated surface. A large number of local polarization curves (about 10 curves) were plotted in different sites to ensure that all potential weak points (except oxide microparticles) are considered. As obtained results were very reproducible, only two typical curves are shown. The matrix of $316 \mathrm{~L}(\mathrm{WS})$ without mixed oxide microparticles exhibits passive behavior, Fig. 9. No stable and metastable pitting is observed in the anodic domain. Although the matrices of $316 \mathrm{~L}(\mathrm{WS})$ and $316 \mathrm{~L}(\mathrm{SLM})$ are
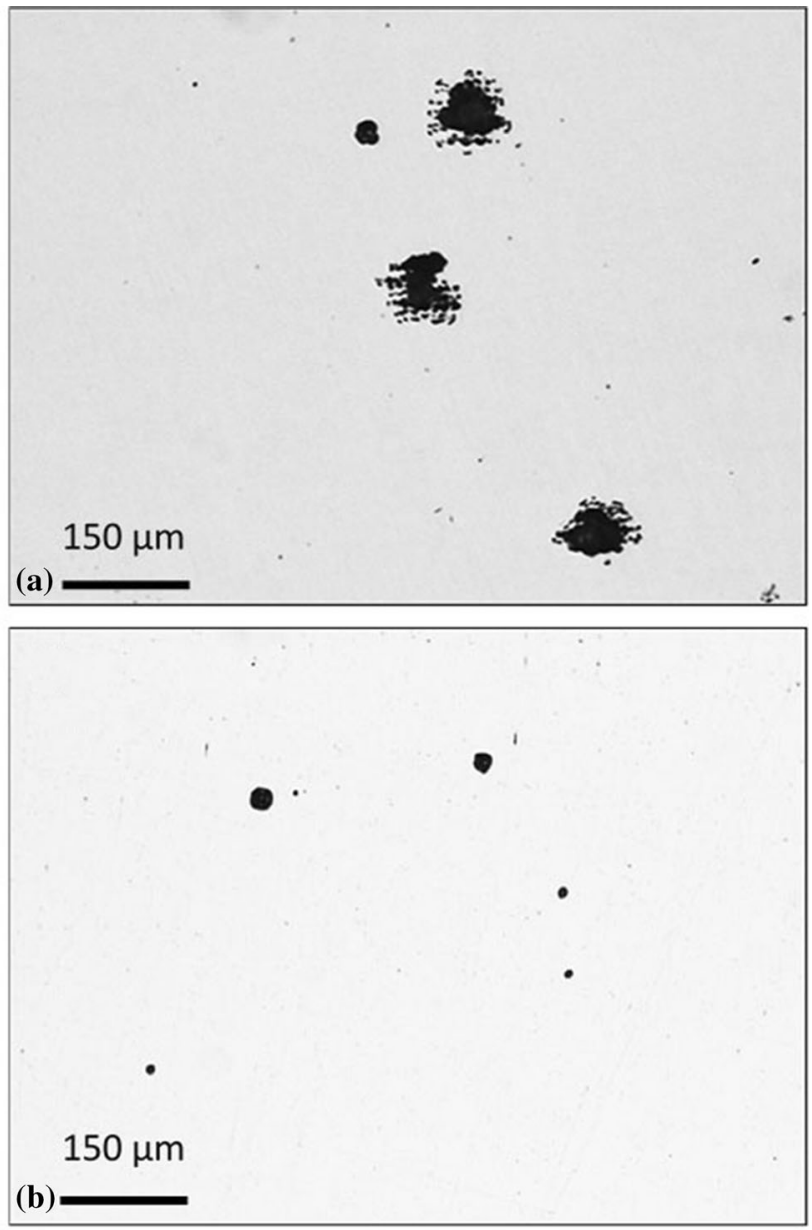

Fig. 8 Optical micrographs of the surface after the polarization curve: (a) 316L(WS) and (b) 316L(SLM-1050)

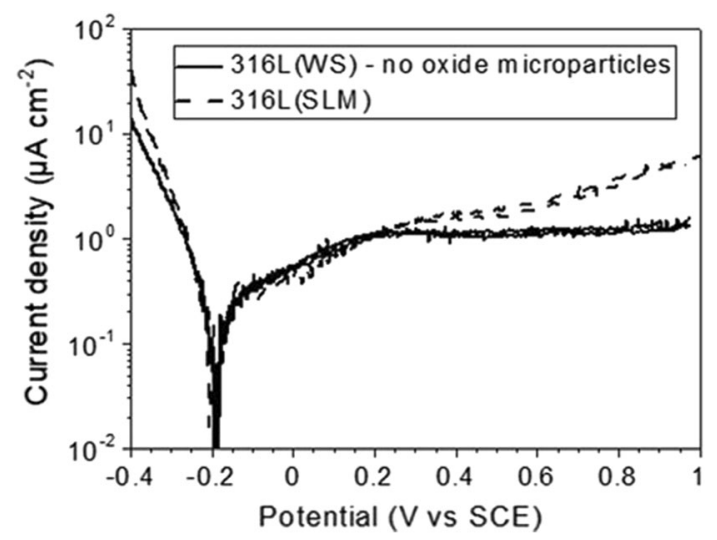

Fig. 9 Local polarization curves $\left(3.5 \% \mathrm{NaCl}\right.$ à $25^{\circ} \mathrm{C}, 1 \mathrm{mV} \mathrm{s}{ }^{-1}$, capillary diameter of $154 \mu \mathrm{m}$ ) after surface preparation of 316L(WS) and $316 \mathrm{~L}(\mathrm{SLM})$

different in terms of average grain size and PREN, they have similar corrosion behavior in $3.5 \% \mathrm{NaCl}$ at $25{ }^{\circ} \mathrm{C}$ (passive behavior, no pitting). These results show that mixed oxide microparticles present in the alloy elaborated by classical processing are precursor sites for pitting.

Local polarization curves were plotted in sites of 316L(SLM) under the same experimental conditions, Fig. 9. 
Several grains and grain boundaries are again present within the investigated surface (Fig. 1b). As it was already found at the macroscale, no pitting potential can be defined from local polarization curves. $316 \mathrm{~L}$ (SLM) has passive behavior in $3.5 \%$ $\mathrm{NaCl}$. The current density in the passive range is slightly greater than that measured on $316 \mathrm{~L}$ (WS). This is mainly due to the fact that the native passive film formed on $316 \mathrm{~L}$ (SLM) contains a higher density of dopants than the passive film on 316L(WS), Fig 6.

The pitting potential of $316 \mathrm{~L}(\mathrm{SLM}-1050)$ was found to be lower than the value expected from the linear relationship between the pitting potential and the PREN, Fig. 7(b). The presence of carbides revealed by XPS (section 3.2) greatly reduces the corrosion resistance of $316 \mathrm{~L}$ (SLM-1050) compared to that expected with its PREN value. Other studies (Ref 18, 37) have revealed that chromium carbides are precursor sites in $316 \mathrm{~L}$ stainless steel. The positive influence of the ratio $\mathrm{O}^{2-}$ $\mathrm{OH}^{-}$in the native passive film (section 3.2) is then counterbalanced by the negative role of carbides. The corrosion resistance of $316 \mathrm{~L}$ elaborated by SLM can increase after certain heat treatment, while others may reduce it (Ref 17, 18, 28, 29). It depends on modifications of the microstructure and physicalchemical properties of the passive film formed after aging in aqueous solutions.

\section{Conclusions}

The corrosion behavior of $316 \mathrm{~L}(\mathrm{WS}), 316 \mathrm{~L}(\mathrm{SLM})$ and 316L(SLM-1050) was analyzed considering their microstructure, residual stresses and the physical-chemical properties of native passive films. Obtained results show that the PREN and the average grain size are not the first-order parameters controlling pitting corrosion of the studied alloys. Precursor sites in $316 \mathrm{~L}(\mathrm{WS}$ ) are mixed oxide particles (with $\mathrm{Ca}, \mathrm{Al}, \mathrm{Mg}$, Ti...). In the absence of mixed oxide particles, 316L(WS) has the same corrosion behavior than $316 \mathrm{~L}(\mathrm{SLM})$ in $3.5 \% \mathrm{NaCl}$ at $25{ }^{\circ} \mathrm{C}$ (passive behavior with no pitting potential). Therefore, the inclusion/particles cleanliness is the first-order parameter explaining differences between 316L(WS) and 316L(SLM). After heat treatment at $1050{ }^{\circ} \mathrm{C}$ for 6 hours, carbides are precursor sites in 316L(SLM-1050).

\section{Open Access}

This article is licensed under a Creative Commons Attribution 4.0 International License, which permits use, sharing, adaptation, distribution and reproduction in any medium or format, as long as you give appropriate credit to the original author(s) and the source, provide a link to the Creative Commons licence, and indicate if changes were made. The images or other third party material in this article are included in the article's Creative Commons licence, unless indicated otherwise in a credit line to the material. If material is not included in the article's Creative Commons licence and your intended use is not permitted by statutory regulation or exceeds the permitted use, you will need to obtain permission directly from the copyright holder. To view a copy of this licence, visit http://creativecommons.org/licenses/by/4.0/.

\section{References}

1. Y. Oh, C. Zhou, and S. Behdad, Part Decomposition and AssemblyBased (Re) Design for Additive Manufacturing: A Review, Addit. Manuf., 2018, 22, p 230-242

2. G.H. Loh, E. Pei, D. Harrison, and M.D. Monzón, An Overview of Functionally Graded Additive Manufacturing, Addit. Manuf., 2018, 23, p 34-44

3. G. Sander, S. Thomas, V. Cruz, M. Jurg, N. Birbilis, X. Gao, M. Brameld, and C.R. Hutchinson, On the Corrosion and Metastable Pitting Characteristics of 316L Stainless Steel Produced by Selective Laser Melting, J. Electrochem. Soc., 2017, 164, p C250-C257

4. C. Wang, X. Tan, E. Liu, and S.B. Tor, Process Parameter Optimization and Mechanical Properties for Additively Manufactured Stainless Steel 316L Parts by Selective Electron Beam Melting, Mater. Des., 2018, 147, p 157-166

5. F. Rosa, S. Manzoni, and R. Casati, Damping Behavior of 316L Lattice Structures Produced by Selective Laser Melting, Mater. Des., 2018, 160, p 1010-1018

6. T. Kurzynowski, K. Gruber, W. Stopyra, B. Kuźnicka, and E. Chlebus, Correlation Between Process Parameters, Microstructure and Properties of 316 L Stainless Steel Processed by Selective Laser Melting, Mater. Sci. Eng. A, 2018, 718, p 64-73

7. S. Gorsse, C. Hutchinson, M. Gouné, and R. Banerjee, Additive Manufacturing of Metals: A Brief Review of the Characteristic Microstructures and Properties of Steels, Ti-6Al-4V and High-Entropy Alloys, Sci. Technol. Adv. Mater., 2017, 18, p 584-610

8. S.M. Yusuf, M. Nie, Y. Chen, S. Yang, and N. Gao, Microstructure and Corrosion Performance of 316L Stainless Steel Fabricated by Selective Laser Melting and Processed through High-Pressure Torsion, J. Alloys Compd., 2018, 763, p 360-375

9. Q. Chao, V. Cruz, S. Thomas, N. Birbilis, P. Collins, A. Taylor, P.D. Hodgson, and D. Fabijanic, On the Enhanced Corrosion Resistance of a Selective Laser Melted Austenitic Stainless Steel, Scripta Mater., 2017, 141, p 94-98

10. A. Kurian and P.M. Siva, A comparison of corrosion resistance of stainless steel fabricated with selective laser melting and conventional processing, Int. J. Chemtech Res., 2014-2015, 7, p 2632-2635

11. Y. Zhang, F. Liu, J. Chen, and Y. Yuan, Effects of Surface Quality on Corrosion Resistance of 316L Stainless Steel Parts Manufactured via SLM, J. Laser Appl., 2017, 29, p 022306

12. A. Amanov, Effect of Local Treatment Temperature of Ultrasonic Nanocrystalline Surface Modification on Tribological Behavior and Corrosion Resistance of Stainless Steel 316L Produced by Selective Laser Melting, Surf. Coat. Technol., 2020, 98, p 126080

13. N.S. Al-Mamun, K.M. Deen, W. Haider, E. Asselin, and I. Shabib, Corrosion Behavior and Biocompatibility of Additively Manufactured 316L Stainless Steel in a Physiological Environment: the Effect of Citrate Ions, Addit. Manuf., 2020, 34, p 101237

14. A.B. Kale, B.K. Kim, D.I. Kim, E.G. Castle, M. Reece, and S.H. Choi, An Investigation of the Corrosion Behavior of 316L Stainless Steel Fabricated by SLM and SPS Techniques, Mater. Charact., 2020, 163, p 110204

15. M. Laleh, A.E. Hughes, S. Yang, J.L. Li, W. Xu, I. Gibson, and M.Y. Tan, Two and Three-Dimensional Characterisation of Localised Corrosion Affected by Lack-of-Fusion Pores in 316L Stainless Steel Produced by Selective Laser Melting, Corros. Sci., 2020, 165, p 108394

16. V. Cruz, Q. Chao, N. Birbilis, D. Fabijanic, P.D. Hodgson, and S. Thomas, Electrochemical Studies on the Effect of Residual Stress on the Corrosion of 316L Manufactured by Selective Laser Melting, Corros. Sci., 2020, 164, p 108314

17. C.S. Zhou, S.Y. Hu, Q.Y. Shi, H.M. Tao, Y.Y. Song, J.Y. Zheng, P. Xu, and L. Zhang, Improvement of Corrosion Resistance of SS316L Manufactured by Selective Laser Melting through Subcritical Annealing, Corros. Sci., 2020, 164, p 108353

18. M. Laleh, A.E. Hughes, W. Xu, N. Haghdadi, K. Wang, P. Cizek, I. Gibson, and M.Y. Tan, On the Unusual Intergranular Corrosion Resistance of 316L Stainless Steel Additively Manufactured by Selective Laser Melting, Corros. Sci., 2019, 161, p 108189

19. M. Atapour, X. Wang, M. Persson, I.O. Wallinder, and Y.S. Hedberg, Corrosion of Binder Jetting Additively Manufactured 316L Stainless Steel of Different Surface Finish, J. Electrochem. Soc., 2020, 167, p 131503 
20. V. Hauk, Structural and Residual Stress Analysis by Nondestructive Methods, Elsevier, Amsterdam, 1997

21. Z. Yang, B. Kan, J. Li, Y. Su, L. Qiao, and A.A. Volinsky, Pitting Initiation and Propagation of X70 Pipeline Steel Exposed to ChlorideContaining Environments, Materials, 2017, 10, p 1076

22. N. Hara, K. Hirabayashi, Y. Sugawara, and I. Muto, Improvement of Pitting Corrosion Resistance of Type 316L Stainless Steel by Potentiostatic Removal of Surface MnS Inclusions, Int. J. Corros., 2012, 482730

23. D. Kong, C. Dong, X. Ni, L. Zhang, H. Luo, R. Li, L. Wang, C. Man, and X. Li, The Passivity of Selective Laser Melted 316L Stainless Steel, Appl. Surf. Sci., 2020, 504, p 144495

24. X. Yue, L. Zhang, Y. Hua, J. Wang, N. Dong, X. Li, S. Xu, and A. Neville, Revealing the Superior Corrosion Protection of the Passive Film on Selective Laser Melted 316L SS in a Phosphate-Buffered Saline Solution, Appl. Surf. Sci., 2020, 529, p 147170

25. J.G. Choi and L.T. Thompson, XPS Study of As-prepared and Reduced Molybdenum Oxides, Appl. Surf. Sci., 1996, 93, p 143-149

26. P. Marcus and J.M. Grimal, The Antogonistic Roles of Chromium and Sulphur in the Passivation of Ni-Cr-Fe Alloys Studied by XPS and Radiochemical Techniques, Corros. Sci., 1990, 31, p 377-382

27. P. Keller and H.H. Strehblow, XPS Investigations of Electrochemically Formed Passive Layers on Fe/Cr-Alloys in $0.5 \mathrm{M} \mathrm{H}_{2} \mathrm{SO}_{4}$, Corros. Sci., 2004, 46, p 1939-1952

28. D. Kong, X. Ni, C. Dong, L. Zhang, C. Man, J. Yao, K. Xiao, and X. Li, Heat Treatment Effect on the Microstructure and Corrosion Behavior of 316L Stainless Steel Fabricated by Selective Laser Melting for Proton Exchange Membrane Fuel Cells, Electrochim. Acta, 2018, 276, p 293-303

29. C. Zhou, J. Wang, S. Hu, H. Tao, B. Fang, L. Li, and Z.L. ZhengJ, Enhanced Corrosion Resistance of Additively Manufactured 316L Stainless Steel After Heat Treatment, J. Electrochem. Soc., 2020, 167, p 141504
30. V. Vignal, H. Krawiec, O. Heintz, and D. Mainy, Passive Properties of Lean Duplex Stainless Steels After Long-Term Ageing in Air Studied using EBSD, AES, XPS and Local Electrochemical Impedance Spectroscopy, Corros. Sci., 2013, 67, p 109-117

31. V. Vignal, H. Krawiec, and S. Le Manchet, Influence of Surface Preparation and Microstructure on the Passivity and Corrosion Behaviour of Duplex Stainless Steels, J. Solid State Electrochem., 2014, 18, p 2947-2954

32. V. Vignal, H. Zhang, O. Delrue, O. Heintz, I. Popa, and J. Peultier, Influence of Long-Term Ageing in Solution Containing Chloride Ions on the Passivity and the Corrosion Resistance of Duplex Stainless Steels, Corros. Sci., 2011, 53, p 894-903

33. N.E. Hakiki, S. Boudin, B. Rondot, and M. Da Cunha Belo, The Electronic Structure of Passive Films Formed on Stainless Steels, Corros. Sci., 1995, 37, p 1809-1822

34. H. Krawiec, V. Vignal, and J. Banas, Local Electrochemical Impedance Measurements on Inclusion-Containing Stainless Steels using Microcapillary-Based Techniques, Electrochim. Acta, 2009, 54, p 6070-6074

35. H. Krawiec, V. Vignal, O. Heintz, R. Oltra, and E. Chauveau, Dissolution of Chromium-Enriched Inclusions and Pitting Corrosion of Resulfurized Stainless Steels, Metall. Mater. Trans. A Phys. Metall. Mater. Sci., 2006, 37A, p 1541-1549

36. V. Rault, V. Vignal, H. Krawiec, and O. Tadjoa, Corrosion Behaviour of Heavily Deformed Pearlitic and Brass-Coated Pearlitic Steels in Sodium Chloride Solutions, Corros. Sci., 2014, 86, p 275-284

37. A.B. Rhouma, T. Amadou, H. Sidhom, and C. Braham, Correlation Between Microstructure and Intergranular Corrosion Behavior of Low Delta-Ferrite Content AISI 316L Aged in the Range $550-700{ }^{\circ} \mathrm{C}, J$. Alloys Compd., 2017, 708, p 871-886

Publisher's Note Springer Nature remains neutral with regard to jurisdictional claims in published maps and institutional affiliations. 